\title{
Bone Langerhans cell histiocytosis with pulmonary involvement in an adult non-smoker: A case report and brief review of the literature
}

\author{
JIE SHEN $^{1}$ and SHICHENG FENG ${ }^{2}$ \\ ${ }^{1}$ Department of Imaging, Nanjing Chest Hospital, Medical School of Southeast University; \\ ${ }^{2}$ Department of Oncology, Zhongda Hospital Affiliated to Southeast University, Nanjing, Jiangsu 210009, P.R. China
}

Received February 29, 2016; Accepted July 27, 2016

DOI: $10.3892 / \mathrm{mco} .2016 .1077$

\begin{abstract}
Langerhans cell histiocytosis $(\mathrm{LCH})$ is a rare disease of unknown cause, which encompasses a set of disorders of multiple organs with various clinical presentations that share the common characteristic of sizeable Langerhans cell infiltration. The clinical spectrum of LCH ranges from solitary bone lesions to involvement of other organs. Lung involvement in LCH may be part of a multisystem disease, which almost exclusively occurs in adult smokers, while it is overlooked or misdiagnosed in the majority of non-smokers. High-resolution computed tomography (HRCT) of the chest is crucial for diagnosis; however, the treatment and prognosis of this disease have not been clearly determined. We herein present the case of a non-smoking adult patient who presented with lower limb pain and was diagnosed via biopsy with $\mathrm{LCH}$ with multisystem involvement, including the bone and lungs. Lytic lesions in the corpus of the sacroiliac joint, sacrum, acetabulum and femoral head by a soft tissue mass were observed on diagnostic CT. In addition, chest HRCT revealed multiple cysts in the bilateral lungs, predominantly in the upper lobes. The final diagnosis of LCH was confirmed by histopathological examination and immunohistochemical staining for CD1a and S-100. Corticosteroid treatment alleviated lower limb pain and improved the patient's quality of life; thus, corticosteroids may be considered as a potential treatment option for patients with LCH.
\end{abstract}

\section{Introduction}

Langerhans cell histiocytosis ( $\mathrm{LCH})$ is a rare disease of unknown etiology characterized by mixed cellular infiltration. Although the etiology of LCH has not been fully elucidated, the gold standard for the diagnosis of $\mathrm{LCH}$ is the presence of

Correspondence to: Dr Shicheng Feng, Department of Oncology, Zhongda Hospital Affiliated to Southeast University, 87 Dingjiaqiao, Gulou, Nanjing, Jiangsu 210009, P.R. China

E-mail: 2465041441@qq.com

Key words: Langerhans cell histiocytosis, non-smoker, computed tomography, lung
Birbeck granules, and positivity for CD1a, S-100 and/or CD45 on pathological examination $(1,2)$. $\mathrm{LCH}$ may occur at any age, although it is more common in children, and has various clinical manifestations, depending on the type and number of systems or organs involved throughout the body (3).

Specific acute symptoms may include local pain, weight loss, fatigue, fever, skin rash and neurological changes, while the bone and lung are the most commonly involved organs (4). It has been reported that the proportion of LCH with lung involvement in adults is higher compared with that in children (4). Furthermore, the disease is self-limited in the majority of pediatric patients, which is not the case in adults. A variety of factors have been implicated in the prognosis of $\mathrm{LCH}$, such as patient age and extent of the disease. Several therapeutic approaches may be considered, including surgery, radiotherapy and chemotherapy; however, there is currently no standard treatment for $\mathrm{LCH}$ patients with multisystem involvement (MS-LCH).

\section{Case report}

A 38-year-old male patient with a 2-year history of left leg pain, involving numbness extending from the left thigh to the knee, was referred to Nanjing Chest Hospital, Medical School of Southeast University. The pain and numbness in the left thigh were aggravated by exertion, such as walking or running, and they improved by rest, although they did not completely resolve. The patient had no history of tobacco or alcohol consumption, trauma or any other significant medical conditions. On physical examination, the patient appeared to be in a good overall condition. Neurological examination revealed normal motor and sensory function, symmetric reflexes, with no evidence of clonus, fasciculations or ataxia. Other findings on physical examination were unremarkable. On admission, the immunoglobulin (Ig) laboratory tests were as follows: IgG, $15.1 \mathrm{~g} / \mathrm{l}$ (normal range, 7-16 g/l); IgA, $3.87 \mathrm{~g} / 1$ (normal range, 0.7-4.0 g/l); and IgM, $1.16 \mathrm{~g} / \mathrm{l}$ (normal range, 0.4-2.3 g/l). The erythrocyte sedimentation rate (normal range, $0-20 \mathrm{~mm} / \mathrm{h}$ ) and high-sensitivity $\mathrm{C}$-reactive protein levels $(0-1.0 \mathrm{mg} / \mathrm{l})$ were mildly elevated $(31 \mathrm{~mm} / \mathrm{h}$ and $44.5 \mathrm{mg} / \mathrm{l}$, respectively). Blood cell count, urinalysis, serum chemistry, electrolytes and tumor 

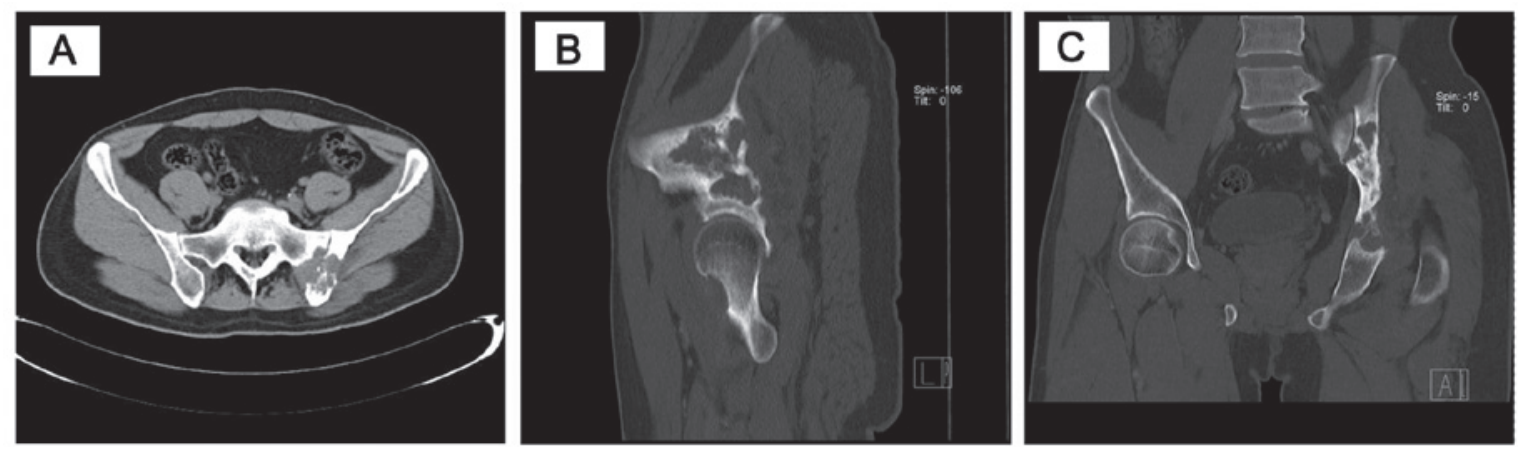

Figure 1. (A) Computed tomography multiplanar reconstruction images showing an osteolytic lesion around the left sacroiliac joint with surrounding edematous soft tissues. (B) Coronal and (C) sagittal plane multiplanar reconstruction of the pelvis showing a bone lesion on the left, with reactive sclerosis.
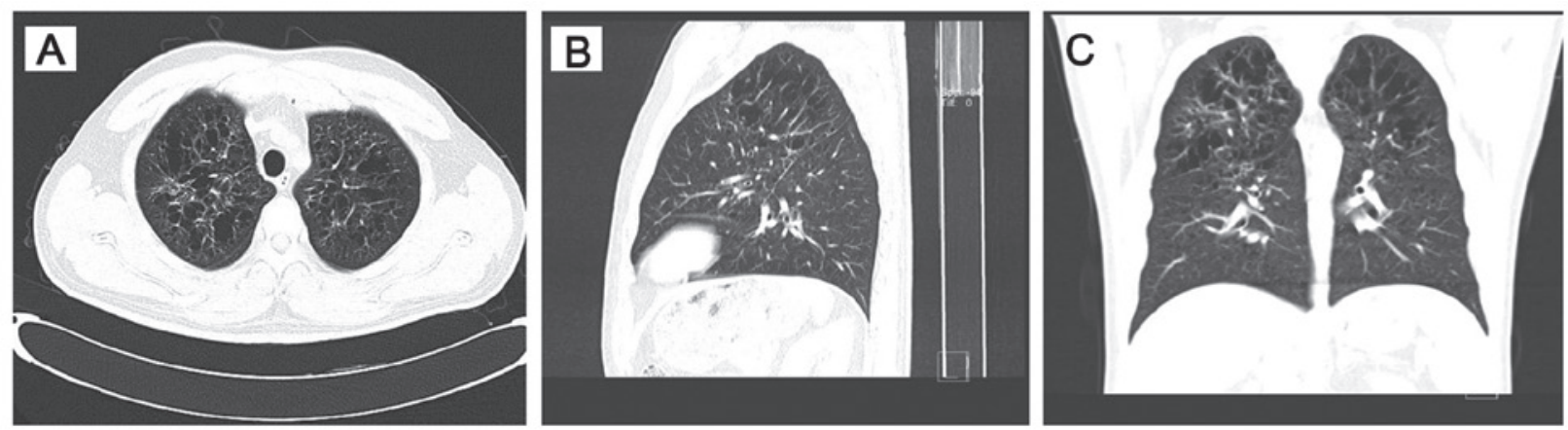

Figure 2. (A-C) High-resolution computed tomography images showing numerous bilateral pulmonary cystic foci of varying sizes, occasionally with a partially thin or thick cystic wall. Multiple cysts associated with extensive consolidation (with a predominant upper-lobe distribution) were a characteristic feature. The lung involvement in our patient was asymptomatic and diagnosis was confirmed by bone lesion biopsy.

markers were within normal ranges. Pulmonary function is frequently normal at presentation.

The images obtained by a multidetector computed tomography $(\mathrm{CT})$ device were reconstructed in a variety of planes and interpreted in soft tissue, bone or lung windows. Pulmonary and pelvic diagnostic CT examination revealed the distribution of the disease: The corpus of the sacroiliac joint, sacrum, acetabulum and femoral head were occupied by a destructive soft tissue mass (Fig. 1).

In addition, high-resolution CT (HRCT) of the chest revealed bilateral, diffuse infiltration of the lungs by numerous cysts, mainly distributed in the upper and middle lung fields, while the surrounding pulmonary parenchyma was normal (Fig. 2). A CT-guided percutaneous needle biopsy was performed and the results confirmed the diagnosis of LCH. Histopathologically, a heterogeneous admixture of inflammatory cells, including numerous eosinophils, rare multinucleated giant cells, mononuclear cells and foam cells, was observed (Fig. 3). The histopathological examination revealed proliferation of histiocytes with an infiltration by eosinophils. Immunohistochemically, the histiocytes were $\mathrm{S}-100^{+}, \mathrm{CD} 63^{+}, \mathrm{CD}^{2} \mathrm{a}^{+}, \mathrm{CD} 8^{+}$(partially), vimentin ${ }^{+}, \mathrm{Ki}-67^{+}$ $(\sim 15 \%)$ and langerin ${ }^{+}$. Although the patient was diagnosed with $\mathrm{LCH}$, the aggressive appearance of a destructive lesion on CT images made it necessary to conduct a biopsy in order to establish a definitive diagnosis. There was no evidence of involvement of any other organ on magnetic resonance imaging (MRI) of the head and abdomen. Corticosteroid treatment was administered to the patient. No further treatment was recommended, such as combination chemotherapy, surgery or radiotherapy. Corticosteroid therapy was continued for a few months. There has been no evidence of disease progression during follow-up.

Written informed consent was obtained from the patient regarding the publication of this case report and any accompanying images.

\section{Discussion}

$\mathrm{LCH}$, formely referred to as histiocytosis $\mathrm{X}$, is diagnosed according to clearly established criteria. $\mathrm{LCH}$ is a rare,complex and poorly understood disorder that is associated with a variety of clinical manifestations. $\mathrm{LCH}$ is characterized by the abnormal proliferation of bone marrow-derived Langerhans cells and may be divided into three types: Eosinophilic granuloma, Hand-Schuller-Christian disease and Lettere-Siwe disease $(5,6)$. Histopathological examination is crucial for the diagnosis of $\mathrm{LCH}$, and immunoreactivity for S-100 and $\mathrm{CD1a}$, as well as the presence of Birbeck granules on electron microscopy examination, provide helpful information (7-9), as does the presence of CD45, CD56-positive cells $(10,11)$.

$\mathrm{LCH}$ is generally considered to be a pediatric disease and more frequently occurs in males $(5,6,12)$. Adults are rarely diagnosed with $\mathrm{LCH}$, with an estimated annual incidence of 1-2 cases per million individuals (6). However, the patient in the present case was aged 38 years. The clinical presentation of LCH is highly variable. In addition, a stratification system depending on the extent and localization of the disease at the 

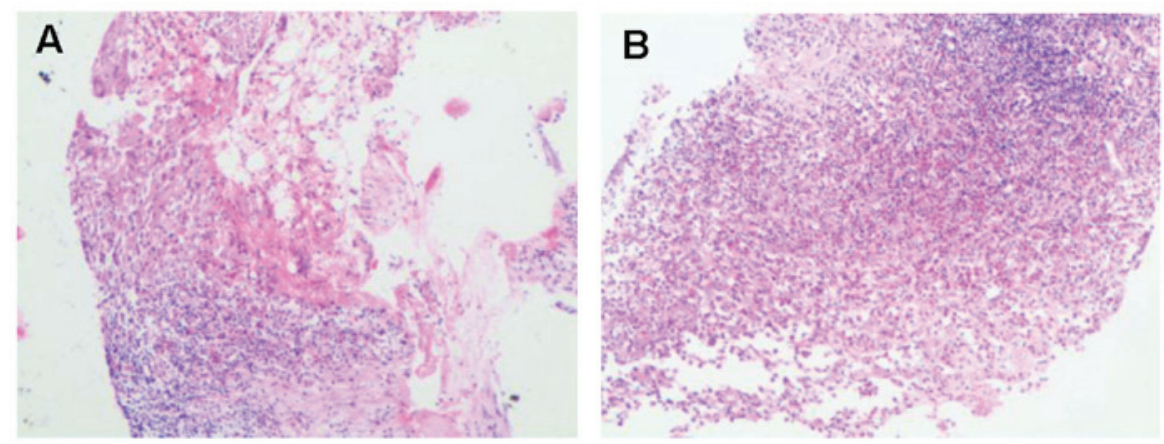

Figure 3. (A and B) Histopathological examination of the lesion in the sacroiliac joint revealed that the lesion mainly comprised a mixture of polygonal cells with slightly granular cytoplasm; the cell nuclei displayed frequent grooves and were occasionally folded. An admixture of other inflammatory cells, including numerous eosinophils, rare multinucleated giant cells, mononuclear cells and foam cells, was also present (hematoxylin and eosin staining; magnification, x100).

time of evaluation was adopted by the LCH study group, which classified the disease into single-system LCH (SL-LCH) and MS-LCH (13); the latter may be further subdivided into lowand high-risk MS-LCH $(14,15)$. We herein report a rare adult case of $\mathrm{LCH}$ presenting with lung and bone involvement, which was classified as high-risk MS-LCH. LCH accounts for $<1 \%$ of tumor-like bone lesions (16). Adult LCH patients are often afflicted by chronic pain, such as back pain, and fatigue of undetermined etiology. The pain may localize to specific sites, despite the lack of an identifiable pathology. The most frequent sites are the skull (26\%) and jaw (9\%), followed in decreasing order of frequency by the long tubular bones, pelvis, ribs and the spine (17-19); rarely, the lesion may be located in the pelvis (20).

When a bone lesion is encountered, $\mathrm{LCH}$ may not be considered in the differential diagnosis, as this disease is rare and may manifest as a heterogeneous spectrum of lesions, ranging from a single bone lesion to MS-LCH. CT and MRI are effective approaches to delineating the extent of osseous destruction and soft tissue involvement. In adults with $\mathrm{LCH}$ confirmed by biopsy, a chest CT is necessary to assess the extent of the disease at presentation, along with laboratory evaluation. However, a bone biopsy is required for the diagnosis of LCH in certain cases, in order to rule out other types of lesions, such as hypoadrenalism, metastatic carcinoma, lymphoma/myeloma, osteomyelitis, osteoblastoma, aneurysmal bone cyst and Ewing's sarcoma (21).

In the majority of the cases, $\mathrm{LCH}$ in adults manifests as a widespread, multisystem disease, with the lung being the most common site of extraosseous involvement. The high proportion of cases with pulmonary involvement is the most conspicuous difference between adult and pediatric LCH (4). Although $\leq 20-30 \%$ of adult LCH patients have isolated pulmonary lesions, the occurrence of $\mathrm{LCH}$ in the pelvis, either as a primary isolated manifestation of the disease or as part of systemic disease, is rare. In adults, lung involvement in LHC often coexists with involvement of other tissues/organs, is poorly recognized and frequently overlooked. Common symptoms of pulmonary LCH (PLCH) include cough, dyspnea and chest pain, and they are crucial for diagnosis. However, $25 \%$ of patients with PLCH are asymptomatic and the disease is diagnosed due to incidentally discovered radiographic abnormalities (22), as was the case in our patient.

Although the clinical manifestations and imaging findings of PLCH are different in each stage of the disease, HRCT was reported to be important in the diagnosis of PLCH (23), and familiarity with characteristic imaging findings is required for accurate and timely diagnosis. In addition, imaging methods (particularly HRCT) play a fundamental role in diagnosing and assessing the stage of LCH, ensuring administration of appropriate treatment and patient monitoring. In the early stages of the disease, the typical manifestation of PLCH on radiological examination is diffuse bilateral and symmetric ill-defined small or cavitated nodules (both of which may resolve), ranging from 2 to $10 \mathrm{~mm}$ in diameter and predominantly located in the middle or upper pulmonary fields, with sparing the costophrenic angles. However, other diseases may present with similar findings in the lungs, and the differential diagnosis must include sarcoidosis, silicosis, metastases, miliary tuberculosis, bronchiectasis and emphysema. Furthermore, the imaging presentation of PLCH may vary at clinical onset. If the lesions persist or progress, classic imaging findings typically include small centrilobular nodules or thickand thin-walled cysts of varying sizes, with mid- to upper-lung distribution. Although LCH occurs in patients below 24 years of age (24), however, the cavitation and the development of cysts is diagnosed at a later stage of the disease progression.

The treatment and prognosis, as well as the clinical course of $\mathrm{LCH}$, remain to be fully determined, particularly in adult patients (25). Unlike LCH in children, due to the current lack of standard therapeutic regimens for adult $\mathrm{LCH}$, age, extent of the disease and dysfunction of vital organs are considered as the major factors affecting the selection of the optimal treatment. Lung involvement is almost always associated with smoking $(21,26)$; however, the present case indicated that cigarette smoking may not always be associated with the pathogenesis of PLCH. It was reported that LCH may be successfully treated by controlling the patient's smoking habits (27); however, smoking cessation is not always effective (28). There are several suggested potential mechanisms through which smoking may promote PLCH in certain individuals, although the association between cigarette smoking and progression or regression of adult LCH has not been fully elucidated. Particularly in non-smokers, the underlying mechanisms of $\mathrm{LCH}$ remain to be determined. Novel therapies for $\mathrm{LCH}$ are urgently required, as smoking cessation only showed limited efficacy. Other treatments, such as corticosteroids, have been reported in adult LCH. The corticosteroid regimen used in the present case was selected based on case series reports of successful treatment $(28,29)$; however, 
the efficacy of such treatment in non-smoking adults has not been determined. In the present case, corticosteroids were used due to their efficacy in adults with MS-LCH, as LCH lesions do not progress following corticosteroid therapy, although cystic disease may be irreversible. In the classic presentation of isolated pulmonary LCH in non-smoking adults, the condition may resolve with corticosteroids alone. If the treatment effect is not significant, chemotherapy with cladribine may be required $(30,31)$. However, although different regimens have exhibited some efficacy in the treatment of adult MS-LCH (32), no specific intervention has shown any benefit with regard to patient survival (33), with rather low complete or partial remission rates (34). The mortality rate of patients with $\mathrm{LCH}$ receiving no treatment is high, and the survival probability at 5 years post-diagnosis of patients with MS-LCH is mildly inferior to that of patients with SL-LCH (4).

As the mechanisms underlying $\mathrm{LCH}$ remain unclear, further studies with a large sample size are required to avoid misdiagnosis in clinical practice.

$\mathrm{LCH}$ is a rare disease with a variable clinical presentation. Systematic analysis of clinical presentation, imaging findings and immunohistochemistry is necessary to accurately diagnose $\mathrm{LCH}$. Bone involvement is common in adults with $\mathrm{LCH}$ and may be indicative of SL-LCH or MS-LCH. Chronic pain may be the first or sole manifestation of the disease. As the lungs are the most common site of extraosseous involvement, $\mathrm{LCH}$ should be considered in smokers as well as in non-smokers. Imaging, particularly HRCT, is key to the diagnosis and is useful for detecting lung injury at each stage of pulmonary involvement in $\mathrm{LCH}$, from small centrilobular nodules to diffuse cysts and fibrosis. Accurate diagnosis is crucial for improving prognosis. In the present case, corticosteroids were used for the treatment of $\mathrm{LCH}$, achieving a positive outcome.

\section{References}

1. Herwig MC, Wojno T, Zhang Q and Grossniklaus HE: Langerhans cell histiocytosis of the orbit: Five clinicopathologic cases and review of the literature. Surv Ophthalmol 58: 330-340, 2013.

2. Kasper EM, Aguirre-Padilla DH, Alter RY and Anderson M: Histiocytosis X: Characteristics, behavior and treatments as illustrated in a case series. Surg Neurol Int 2: 57, 2011.

3. Gasent Blesa JM, Alberola Candel V, Solano Vercet C, Laforga Canales J, Semler C, Pérez Antolí MR and Rodríguez-Galindo C: Langerhans cell histiocytosis. Clin Transl Oncol 10: 688-696, 2008.

4. Aricò M, Girschikofsky M, Généreau T, Klersy C, McClain K, Grois N, Emile JF, Lukina E, De Juli E and Danesino C: Langerhans cell histiocytosis in adults. Report from the International Registry of the Histiocyte Society. Eur J Cancer 39: 2341-2348, 2003.

5. Grana N: Langerhans cell histiocytosis. Cancer Control 21: 328-334, 2014

6. El Demellawy D, Young JL, De Nanassy J, Chernetsova E and Nasr A: Langerhans cell histiocytosis: A comprehensive review. Pathology 47: 294-301, 2015.

7. Pileri SA, Grogan TM, Harris NL, Banks P, Campo E, Chan JK, Favera RD, Delsol G, De Wolf-Peeters C, Falini B, et al: Tumours of histiocytes and accessory dendritic cells: An immunohistochemical approach to classification from the International Lymphoma Study Group based on 61 cases. Histopathology 41: $1-29,2002$.

8. Herwig MC, Wojno T, Zhang Q and Grossniklaus HE: Langerhans cell histiocytosis of the orbit: Five clinicopathologic cases and review of the literature. Surv Ophthalmol 58: 330-340, 2013.

9. Histiocytosis syndromes in children. Writing Group of the Histiocyte Society. Lancet 1: 208-209, 1987.
10. Kawase T, Hamazaki M, Ogura M, Kawase Y, Murayama T, Mori Y, Nagai H, Tateno M, Oyama T, Kamiya Y, et al: CD56/NCAM-positive Langerhans cell sarcoma: A clinicopathologic study of 4 cases. Int J Hematol 81: 323-329, 2005.

11. Kasper EM, Aguirre-Padilla DH, Alter RY and Anderson M: Histiocytosis X: Characteristics, behavior and treatments as illustrated in a case series. Surg Neurol Int 2: 57, 2011.

12. Allen CE, Ladisch S and McClain KL: How I treat Langerhans cell histiocytosis. Blood 126: 26-35, 2015.

13. Abla O, Egeler RM and Weitzman S: Langerhans cell histiocytosis: Current concepts and treatments. Cancer Treat Rev 36: 354-359, 2010.

14. Allen CE and McClain KL: Langerhans cell histiocytosis: A review of past, current and future therapies. Drugs Today (Barc) 43: 627-643, 2007

15. Lau EG, Stepenaskie S, Moran R, Quinn R, Matthew P and Smidt AC: 'Blueberry muffin' rash and large right thigh mass: A unique presentation of Langerhans cell histiocytosis. Dermatol Online J 19: 18568, 2013.

16. Wells PO: The button sequestrum of eosinophilic granuloma of the skull. Radiology 67: 746-747, 1956.

17. Stockschlaeder M and Sucker C: Adult Langerhans cell histiocytosis. Eur J Haematol 76: 363-368, 2006.

18. Kilpatrick SE, Wenger DE, Gilchrist GS, Shives TC, Wollan PC and Unni KK: Langerhans' cell histiocytosis (histiocytosis X) of bone. A clinicopathologic analysis of 263 pediatric and adult cases. Cancer 76: 2471-2484, 1995.

19. Bertram C, Madert J and Eggers C: Eosinophilic granuloma of the cervical spine. Spine (Phila Pa 1976) 27: 1408-1413, 2002.

20. Shi S, Liu Y, Fu T, Li X and Zhao S: Multifocal Langerhans cell histiocytosis in an adult with a pathological fracture of the mandible and spontaneous malunion: A case report. Oncol Lett 8: 1075-1079, 2014

21. Haupt R, Minkov M, Astigarraga I, Schäfer E, Nanduri V, Jubran R, Egeler RM, Janka G, Micic D, Rodriguez-Galindo C, et al: Langerhans cell histiocytosis $(\mathrm{LCH})$ : guidelines for diagnosis, clinical work-up and treatment for patients till the age of 18 years. Pediatr Blood Cancer 60: 175-184, 2013.

22. Satter EK and High WA: Langerhans cell histiocytosis: A review of the current recommendations of the Histiocyte Society. Pediatr Dermatol 25: 291-295, 2008.

23. Tazi A, Soler P and Hance AJ: Adult pulmonary Langerhans' cell histiocytosis. Thorax 55: 405-416, 2000.

24. Martin I, Ballester M, Ruiz Y, Llatjós R, Alarza F and Molina M: Presentation of pulmonary Langerhans cell histiocytosis before the development of lung cysts. Respirol Case Rep 1: 34-35, 2013.

25. Arico M: Langerhans cell histiocytosis in adults: More questions than answers? Eur J Cancer 40: 1467-1473, 2004.

26. Tazi A, Soler P and Hance AJ: Adult pulmonary Langerhans' cell histiocytosis. Thorax 55: 405-416, 2000.

27. Suri HS, Yi ES, Nowakowski GS and Vassallo R: Pulmonary Langerhans cell histiocytosis. Orphanet J Rare Dis 7: 16, 2012.

28. Nquyen K and Tazi A: Langerhans cell histiocytosis in adults. Rev Prat 56: 1863-1871, 2006 (In French).

29. Tazi A: Adult pulmonary Langerhans' cell histiocytosis. Eur Respir J 27: 1272-1285, 2006.

30. Lorillon G, Bergeron A, Detourmignies L, Jouneau S, Wallaert B, Frija J and Tazi A: Cladribine is effective against cystic pulmonary Langerhans cell histiocytosis. Am J Respir Crit Care Med 186: 930-932, 2012.

31. Grobost V, Khouatra C, Lazor R, Cordier JF and Cottin V: Effectiveness of cladribine therapy in patients with pulmonary Langerhans cell histiocytosis. Orphanet J Rare Dis 9: 191, 2014.

32. Minkov M, Grois N, Heitger A, Pötschger U, Westermeier T and Gadner H: Treatment of multisystem Langerhans cell histiocytosis. Results of the DAL-HX 83 and DAL-HX 90 studies. DAL-HX Study Group. Klin Padiatr 212: 139-144, 2000.

33. Vassallo R, Ryu JH, Schroeder DR, Decker PA and Limper AH: Clinical outcomes of pulmonary Langerhans'-cell histiocytosis in adults. N Engl J Med 346: 484-490, 2002.

34. Baumgartner I, Von Hochstetter A, Baumert B, Luetolf U and Follath F: Langerhans'-cell histiocytosis in adults. Med Pediatr Oncol 28: 9-14, 1997. 